\title{
PENGARUH PENERAPAN PROGRAM JAMINAN KESEHATAN NASIONAL (JKN) TERHADAP BIAYA PENGOBATAN DAN CLINICAL OUTCOMES PADA PASIEN ASURANSI KESEHATAN (ASKES) DIABETES MELLITUS TIPE II RAWAT JALAN DI RSPAD GATOT SOEBROTO
}

\section{THE EFFECT OF NATIONAL HEALTH SECURITY PROGRAM IMPLEMENTATION ON TREATMENT COST, CLINICAL OUTCOMES AND LIFE QUALITY OF HEALTH INSURANCE OUTPATIENTS OF DIABETES MELLITUS TYPE II IN GATOT SOEBROTO CENTRAL ARMY HOSPITAL}

\author{
Anggraini Tri Astika1, Yusi Anggriani'2 ${ }^{2}$ Yetti Hersunaryati ${ }^{3}$ \\ 1) Fakultas Farmasi, Program Magister Farmasi, Universitas Pancasila \\ 2) Fakultas Farmasi, Program Magister Farmasi, Universitas Pancasila \\ 3) RSPAD Gatot Soebroto \\ Penulis Korespondensi: \\ Anggraini Tri Astika \\ Universitas Pancasila \\ anggrainitriastika@gmail.com
}

\begin{abstract}
ABSTRAK
Menurut Undang-Undang No. 24 Tahun 2011 Jaminan Sosial Nasional diselenggarakan oleh BPJS Kesehatan yang penerapannya dimulai 1 Januari 2014. Pemerintah memberlakukan tarif dengan sistem Ina-CBGs yang sebelumnya menggunakan fee for service. RSPAD Gatot Soebroto termasuk salah satu rumah sakit yang mengikuti program JKN, harus menggunakan sistem InaCBGs dimana pengobatan pasien sesuai paket berdasarkan diagnosis pasien. Tujuan penelitian ini adalah mengetahui gambaran pengaruh pelaksanaan JKN terhadap biaya pengobatan, clinical outcomes dan kualitas hidup pada pasien DM tipe II di RSPAD Gatot Soebroto. Penelitian ini menggunakan desain longitudinal time series dengan rentang waktu penelitian yaitu 18 bulan, meliputi 189 pasien. Data dianalisis dengan uji perbedaan (Independent samples test, Mann Whitney Test, One Way Anova, Kruscall-Wallis dan Wilcoxon). Hasil penelitian menunjukkan perbedaan bermakna meliputi biaya pengobatan $(p=0,000)$, dan biaya obat $D M(p=0,02)$ dengan adanya peningkatan sesudah JKN. Sedangkan tidak terdapat perbedaan bermakna sebelum dan sesudah JKN pada jumlah biaya obat total $(p=0,674)$.
\end{abstract}

Kata Kunci: Biaya pengobatan, Jaminan Kesehatan Nasional, RSPAD Gatot Soebroto, DM Tipe II 


\section{JURNAL INOVASI \\ FARMASI INDONESIA}

(JAFI)

ABSTRACT

According to Law No. 24 Year 2011, National Social Security was held by National Healthcare Security, the implementation of which started on the 1st of January 2014. The government imposed a rate with Ina-CBGs system replacing fee for service. Gatot Soebroto Central Army Hospital, one of the hospitals that joins National Health Security Program, consequently had to use Ina-CBGs system in which patient treatment is according to the package based on patient diagnosis. The aim of this study is to find out the effect of National Health Security on cost treatment in patients of DM type II in Gatot Soebroto Central Army Hospital. This study used longitudinal time series design with a research time span of 18 months, covering 189 patients. Data were analyzed with difference test (Independent samples test, Mann Whitney Test, One Way Anova, Kruscall-Wallis and Wilcoxon). The result of the study showed significant difference covering the treatment cost $(p=0.000)$, and DM drug cost $D M(p=0.02)$ with an increase after National Health Security. Whereas there was no significant difference before and after National Health Security for the total drug cost $(p=0.674)$.

Keywords : Treatment cost, National Health Security, Gatot Soebroto Central Army Hospital, DM type II

\section{PENDAHULUAN}

Asuransi kesehatan diperlukan untuk dapat mengurangi risiko masyarakat menanggung biaya kesehatan dari kantong sendiri (out of pocket). Semua asuransi mulai dari Askes, Jamkesmas, Jamkesda, Asabri dan jaminan kesehatan yang dikelola swasta kecuali asuransi swasta digabung dalam suatu Badan Penyelenggara Jaminan Sosial (BPJS) menjadi Jaminan Kesehatan Nasional (JKN) (Kemenkes, 2014).

Terdapat perbedaan metode asuransi kesehatan ASKES setelah bergabung dengan BPJS. Sebelum tergabung dalam BPJS/JKN, ASKES dalam asuransi kesehatannya menggunakan metode fee for service (FFS). FFS menggunakan metode bahwa biaya pengobatan dan obat diberikan berdasarkan pelayanan. Sementara itu JKN menggunakan metode yang berbeda dimana biaya pengobatan berdasarkan paket sesuai dengan diagnosa pasien atau disebut juga dengan metode Indonesian Case Base Groups (Ina-CBGs) (Kemenkes, 2014).

Berdasarkan hasil penelitian Padmawati (2014), diketahui bahwa 772 kasus dari total 1231 kasus memiliki tarif rumah sakit yang lebih besar dari tarif Ina-CBGs dengan total biaya pelayanan. Beberapa hambatan dalam penerapan tarif Ina-CBGs pada program JKN 2014 yang menyebabkan rumah sakit merugi yakni kesalahan penulisan diagnosis penyakit, ketidaklengkapan persyaratan peserta, belum adanya clinical pathway, dan masih adanya urun biaya bagi pasien.

Biaya perawatan untuk penyakit DM dalam jangka panjang dan rutin merupakan masalah yang menjadi beban tersendiri bagi pasien. Hal tersebut juga menjadi hambatan beberapa rumah sakit termasuk RSPAD Gatot Soebroto yang menjalankan program BPJS Kesehatan sejak 1 Januari 2014, dimana pembayaran menggunakan sistem tarif paket Ina-CBGs.

\section{TUJUAN PENELITIAN}

Mengetahui gambaran pengaruh pelaksanakaan JKN terhadap biaya pengobatan, clinical outcomes dan HRQoL pasien DM tipe II di RSPAD Gatot Soebroto.. 


\section{JURNAL INOVASI \\ FARMASI INDONESIA}

(JAFI)

\section{METODE}

Desain studi penelitian yang digunakan adalah desain studi longitudinal time series menggunakan dimensi waktu retrospektif. Alat yang digunakan kartu rekam medik, dokumen/kuitansi pasien rawat jalan yang didiagnosa DM tipe II dari Instalasi Farmasi Rumah Sakit (IFRS), dokumen/kuitansi dari Instalasi Farmasi Rumah Sakit dan dari bagian keuangan/BPJS center periode Juli 2013-Desember 2014 di RSPAD Gatot Soebroto.

\section{Populasi dan Sampel}

Populasi dalam penelitian ini adalah semua pasien DM tipe II rawat jalan dengan jaminan ASKES di RSPAD Gatot Soebroto periode Juli 2013-Desember 2014. Penetapan sampel menggunakan metode Krejcle-Morgan teknik sampling menghitung besaran sampel 330 pasien. Penelitian pada seluruh data pasien baik rekam medis, pengobatan, biaya pengobatan dengan data pasien lengkap sebanyak 189 pasien sebagai sampel.

\section{Kriteria Inklusi dan Kriteria Eksklusi}

a. Kriteria inklusi

1) Pasien didiagnosa DM tipe II rawat jalan periode Juli 2013- Desember 2014 di RSPAD Gatot Soebroto.

2) Pasien rutin melakukan rawat jalan selama periode Juli 2013- Desember 2014 di RSPAD Gatot Soebroto (dengan minimal 6 kali kontrol dan 3 kali kontrol sebelum JKN).

3) Pasien jaminan ASKES tanpa tambahan manfaat.

b. Kriteria eksklusi

1) Pasien tidak rutin melakukan rawat jalan selama periode Juli 2013-Desember 2014 di RSPAD Gatot Soebroto (dengan minimal 6 kontrol kali kontrol dan 3 kali kontrol sebelum JKN).

2) Pasien jaminan ASKES dengan tambahan manfaat dan tanggungan asuransi kesehatan lain.

3) Pasien jaminan ASKES dengan diagnosa DM tipe II rawat jalan Juli 2013-Desember 2014 di RSPAD Gatot Soebroto yang tidak mempunyai data lengkap.

\section{Analisis}

a. Biaya pengobatan

1) Biaya administrasi, konsultasi + obat 7 hari

$$
=\frac{\text { biaya administrasi, } \text { konsultasi }+ \text { obat } 7 \text { hari }}{\text { total biaya yang dikeluarkan } R S} \times 100 \%
$$

2) Biaya administrasi, konsultasi + obat 23 hari

$$
=\frac{\text { biaya administrasi, } \text { konsultasi }+ \text { obat } 23 \text { hari }}{\text { total biaya yang dikeluarkan } R S} \times 100 \%
$$

3) Biaya administrasi, konsultasi + obat 30 hari

$$
=\frac{\text { biaya administrasi, } \text { konsultasi }+ \text { obat } 30 \text { hari }}{\text { total biaya yang dikeluarkan } R S} \times 100 \%
$$

b. Biaya Obat

1) Biaya obat 7 hari

$$
=\frac{\text { biaya obat } 7 \text { hari }}{\text { biaya obat }} \times 100 \%
$$




\section{JURNAL INOVASI

2) Biaya obat 23 hari

$$
=\frac{\text { biaya obat } 23 \text { hari }}{\text { biaya obat }} \times 100 \%
$$

c. Proporsi biaya obat dibanding biaya pengobatan

$$
=\frac{\text { jumlah biaya obat }}{\text { biaya pengobatan }}
$$

d. Proporsi biaya obat DM dibanding biaya pengobatan

$$
=\frac{\text { jumlah biaya obat } D M}{\text { biaya pengobatan }}
$$

e. Proporsi biaya obat DM dibanding biaya obat total

$$
=\frac{\text { jumlah biaya obat } D M}{\text { biaya obat total }}
$$

f. Proporsi biaya obat non DM dibanding biaya pengobatan

$$
=\frac{\text { jumlah biaya obat non } D M}{\text { biaya pengobatan }}
$$

g. Proporsi biaya obat non DM dibanding biaya obat total

$$
=\frac{\text { jumlah biaya obat non DM }}{\text { biaya obat total }}
$$

h. Kesesuian tarif RS dengan tarif Ina-CBGs pada pasien dengan pengobatan DM tipe II

$$
=\frac{\text { biaya yang dikeluarkan } R S}{\text { biaya yang dibayarkan } B P J S} \times 100 \%
$$

\section{HASIL DAN PEMBAHASAN}

Data-data pada penelitian diperoleh dari RSPAD Gatot Soebroto, BPJS pusat, BPJS cabang Jakarta Pusat, dan Apotek RSPAD Gatot Soebroto.

\section{Data Demografi Pasien}

Data demografi pasien pada penelitian ini meliputi umur, jenis kelamin, dan diagnosis. Pada hasil penelitian data demografi umur pasien menderita penyakit DM yaitu pada rentan umur 6574 tahun sebesar $36.8 \%$ dan pada umur terendah 35-44 tahun sebesar 0,53\%. Hal ini sesuai dengan data dari Proporsi penderita DM meningkat seiring meningkatnya umur (Kemenkes, 2014).

Hasil penelitian menunjukkan bahwa pasien DM tipe II banyak terjadi pada pasien perempuan (58\%) dibandingkan pada pasien laki-laki (42\%). Bintanah menyebutkan bahwa hal ini dipicu oleh adanya persentase timbunan lemak badan pada wanita yang lebih besar dibandingkan dengan laki-laki yang menjadi salah satu faktor yang dapat menurunkan sensitifitas terhadap kerja insulin pada otot dan hati (Widyastuti, 2014).

Pada penelitian ini diketahui adanya perbedaan diagnosis penyakit pasien sebelum JKN kode E.11 sebesar 83\%, kode E.14 sebesar 17\% dan sesudah JKN meningkat pasien yang mendapatkan 2 kode diagnosis (E.11 dan E.14). Dikarenakan RSPAD Gatot Soebroto (tipe A) sebagai rujukan tertinggi.

\section{Biaya Pengobatan}

Jumlah biaya pengobatan sesudah JKN mengalami peningkatan (Gambar 1.) hal tersebut terkait dengan jumlah biaya obat tiap bulan yang diberikan pasien. Penggunaan insulin lebih 


\section{JURNAL INOVASI \\ FARMASI INDONESIA}

(JAFI)

banyak sesudah JKN terkait dengan lama menderita pasien DM. Pasien dengan lama menderita DM > 10 tahun lebih banyak, sehingga dimungkinkan terjadinya komplikasi. Hal tersebut sesuai dengan penelitian Marlina di RS Fatmawati (tipe A) terjadi kenaikan biaya pengobatan sesudah JKN, terkait penggunaan insulin pada pasien dengan komplikasi lebih banyak.

Gambar 1. Biaya Pengobatan

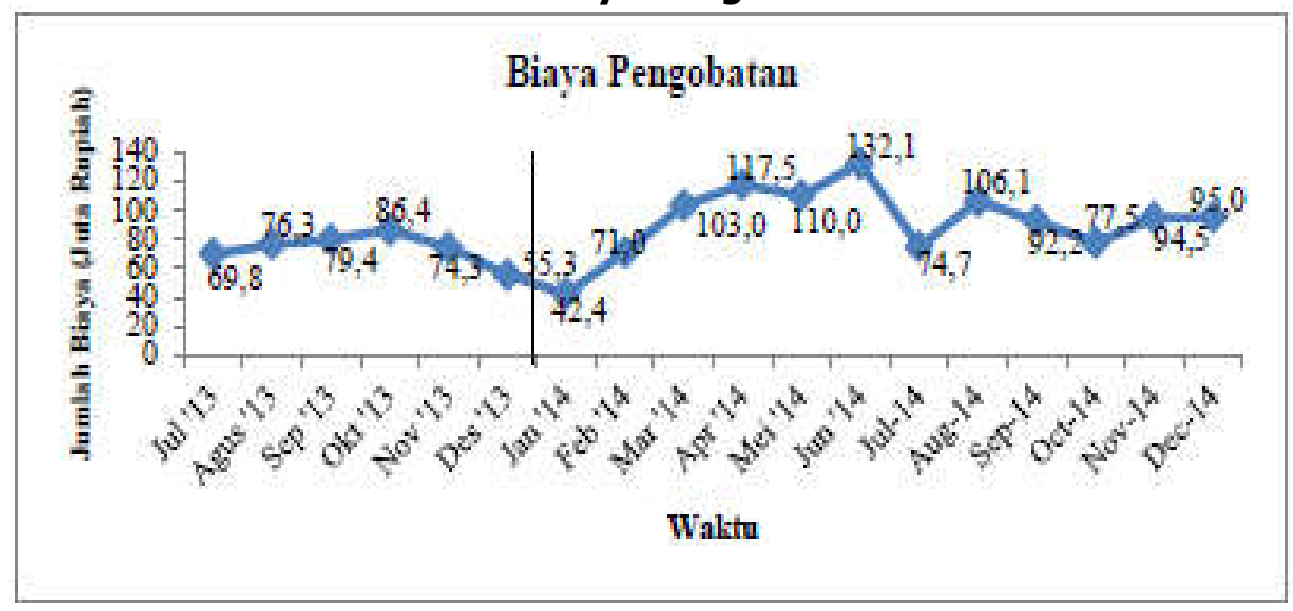

\section{Biaya Obat Total}

Pada hasil peneliatian, menunjukkan tidak terdapat perbedaan yang bermakna biaya obat total sebelum dan sesudah JKN dengan nilai $0,674(p<0,05)$. Pengaruh biaya obat total terkait juga dengan biaya pengobatan rumah sakit yang mengikuti program JKN.

Pengendalikan biaya obat sebelum JKN, dari PT Askes (Persero) menggunakan Daftar Plafon Harga Obat (DPHO) sebagai acuan standar obat yang dijamin. Bila obat yang ditetapkan oleh dokter melebihi standar/tidak masuk dalam DPHO, maka pasien akan menanggung biaya obat yang telah diresepkan oleh dokter. Pada pelaksanaan JKN standar yang digunakan adalah Formularium Nasional dan e-catalogue (Kemenkes, 2013).

\section{Proporsi Biaya Obat Total dengan Biaya Pengobatan}

Berdasarkan hasil penelitian menunjukkan bahwa proporsi antar biaya obat total dan biaya pengobatan tahun 2013 dan tahun 2014 sekitar 49-97\% dengan rata-rata 73\%. Proporsi biaya obat tertinggi pada tahun 2013 (sebelum JKN) Juli 2013 dengan 62.4\% dan terendah Desember 2013 dengan 49\%. Pada tahun 2014 (sesudah JKN) proporsi biaya obat tertinggi pada Januari 2014 (97.9\%) dan terendah pada Desember 2014 sebesar 56.3\%.

Peningkatan pada awal tahun 2014 dikarenakan peralihan pelaksanaan program JKN, sehingga dokter meresepkan obat dalam terapi pengobatan pasien masih memerlukan adaptasi karena adanya perbedaan dalam pedoman untuk obat-obatan.

Berdasarkan hasil tersebut, diketahui bahwa biaya obat total memberikan proporsi yang lebih besar pada pasien Askes DM tipe II rawat jalan daripada biaya pengobatan.

\section{Biaya Obat DM dan Non DM}

\section{Rata-rata Biaya Obat DM dan Biaya Obat Non DM}

Hasil menunjukkan rata-rata biaya obat DM sebelum JKN mengalami penurunan, hal tersebut terjadi juga pada rata-rata biaya obat DM sesudah JKN. Hasil uji statistik menggunakan 


\section{JURNAL INOVASI \\ FARIMASI INDONESIA}

(JAFI)

uji Wilcoxon biaya obat DM terdapat perbedaan yang bermakna sebelum dan sesudah JKN, dengan nilai $0,02(p<0,05)$. Biaya obat Non DM tidak menunjukkan perbedaan yang bermakna yang dilihat berdasarkan hasil statistik 0,0935 $(p<0,05)$.

\section{Proporsi Biaya Obat DM dan Obat Non DM dengan Biaya Pengobatan}

Hasil pada Gambar 2. menunjukkan bahwa proporsi biaya obat DM lebih besar dibandingkan obat non DM terhadap biaya pengobatan pasien. Peningkatan proporsi biaya obat DM dan non DM mengalami peningkatan yang signifikan pada bulan Januari 2014. Hal tersebut sesuai dengan proporsi jumlah total biaya obat. Hal tersebut terkait dengan peralihan pembiayaan dari FFS menjadi Ina-CBGS.

\section{Gambar 2. Proposrsi Biaya Obat DM-Non DM dengan Biaya Pengobatan}

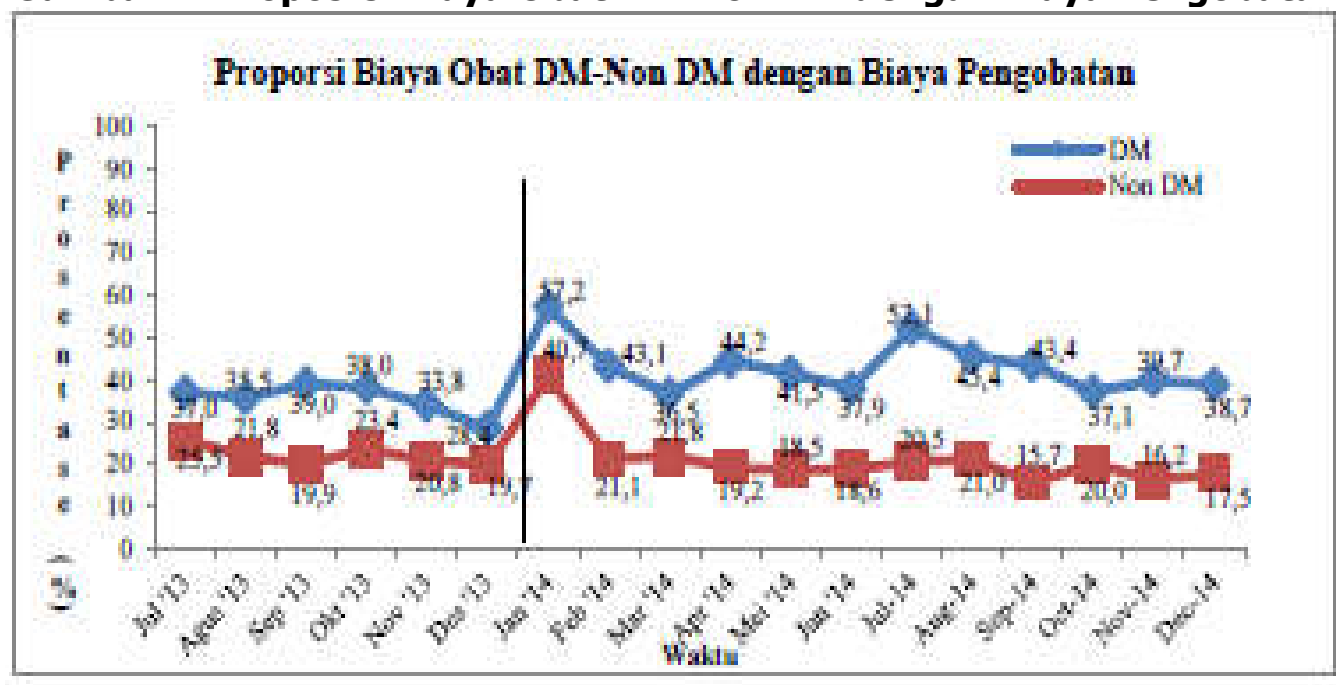

\section{Proporsi Biaya Obat DM dan Obat Non DM dengan Biaya Total Obat}

Proporsi biaya obat DM dan non DM menunjukkan bahwa tidak terdapat jauh perbedaan pada sebelum JKN dan sesudah pelaksanaan program JKN. Proporsi sebelum dan sesudah JKN menunjukkan bahwa biaya obat DM lebih besar dibandingkan obat non DM terhadap biaya total obat.

\section{Kesesuaian Tarif Rumah Sakit (Tujuh Hari) dengan Tarif Paket Ina-CBGs}

Berdasarkan hasil penelitian pada Gambar 3. menunjukkan adanya proporsi kesesuaian rata-rata $80-100 \%$. Pada awal Januari kesesuaian hanya $28 \%$, hal tersebut dapat dikarenakan awal terjadinya perubahan pola klaim. Pada awal program pelaksanaan JKN pelayanan biaya obat kronis 23 hari belum ada sehingga biaya ditanggung oleh penyedia pelayanan kesehatan.

Hal tersebut menunjukkan bahwa pihak penyedia layanan kesehatan dalam hal ini rumah sakit dapat menyesuaikan tarif paket Ina-CBGs pasien rawat jalan dan dapat menggunakan tarif tersebut sesuai dengan kebijakan yang ditetapkan. Pelayanan obat kronis DM dapat ditagihkan 23 hari secara fee for service. Kebijakan tersebut juga menunjukkan bahwa rumah sakit sepenuhnya dapat melakukan pengelolaan tarif untuk biaya pengobatan pasien, walaupun besar tarif ditentukan oleh pemerintah. 
Gambar 3. Kesesuaian Tarif RS 7 Hari dengan Paket Ina-CBGs

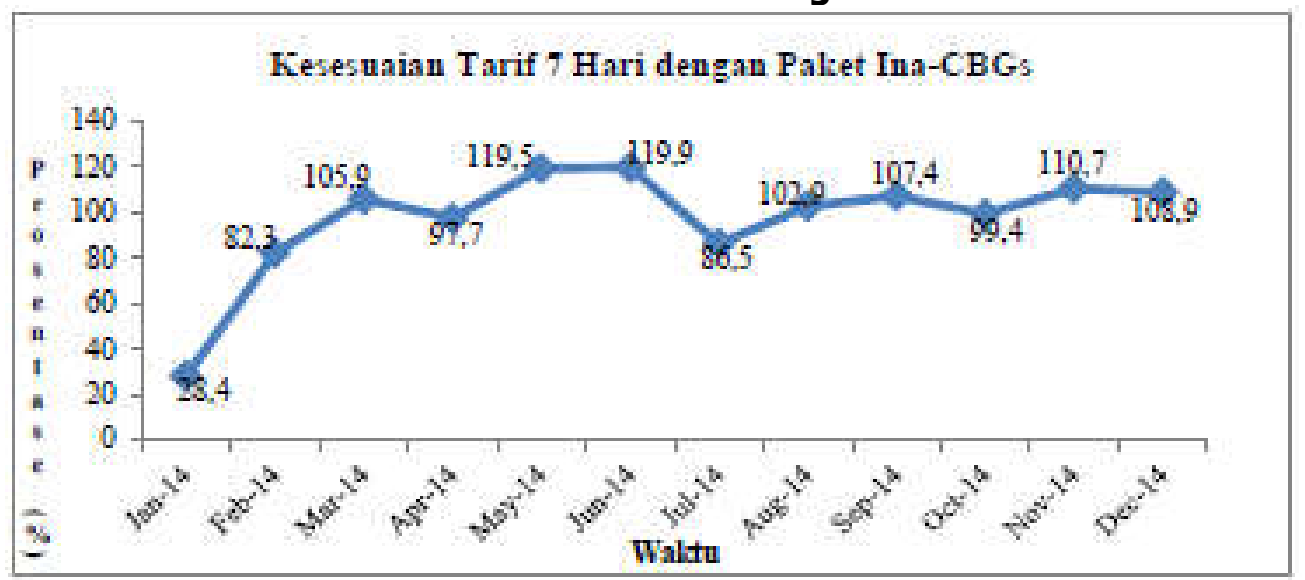

\section{Clinical Outcomes}

Pengontrolan yang rutin dapat dilakukan dengan melihat clinical outcomes pasien dari hasil laboratorium pemeriksaan kadar glukosa darah puasa, 2 jam post prandial dan pemeriksaan HbA1c (ADA, 2014).

\section{Glukosa Darah Puasa (GDP)}

Hasil penelitian, jumlah pasien sebelum JKN dengan kondisi stabil baik 45 pasien (23,8\%). Pada kondisi stabil buruk terdapat 99 pasien (52,4\% dan tidak ada pemeriksaan 16 pasien (8,5\%). Terdapat penurunan jumlah pasien pada pelaksanaan sesudah JKN dengan stabil baik 20 pasien $(10,6 \%)$ dan stabil buruk (58\%). Kenaikan terjadi pada sesudah pelaksaan JKN dimana 41 pasien tidak melakukan pemeriksaan GDP.

Penilaian GDP dilakukan pada hasil pemeriksaan 3 bulan terakhir periode sebelum jkn dan periode sesudah JKN (Oktober, November, dan Desember). Stabil baik jika GDP 100-125 mg/dL dengan penyakit penyerta masih dianggap normal. Stabil buruk jika GDP $<100-125 \mathrm{mg} / \mathrm{dL}$. Stabil baik jika GDP pada tiga bulan terakhir tidak mengalami meningkatan atau penurunan. Stabil buruk jika GDP pasien tetap pada range GDP buruk.

Gambar 4. Penilaian Glukosa Darah Puasa (GDP)

\begin{tabular}{|c|c|c|c|c|}
\hline \multirow[t]{2}{*}{ PENILAIAN } & \multicolumn{2}{|c|}{2013} & \multicolumn{2}{|c|}{2014} \\
\hline & JUMLAH & $\%$ & JUMLAH & $\%$ \\
\hline Stabil Baik & 45 & 23.8 & 20 & 10.6 \\
\hline Stabil Buruk & 99 & 52.4 & 58 & 30.7 \\
\hline Pemeniksaan $<3$ kali & 29 & 15.3 & 27 & 14.3 \\
\hline \multirow{2}{*}{\multicolumn{5}{|c|}{$\begin{array}{l}\text { Jumlah pemenksaan } 3 \text { bulan } \\
\text { terakhir tidak memenuhi }\end{array}$}} \\
\hline & & & & \\
\hline syarat penilaian & & & 43 & 22.8 \\
\hline Tidak ada pemenksaan & 16 & 8.5 & 41 & 21.7 \\
\hline Jumlah & 189 & 100.0 & 189 & 100.0 \\
\hline
\end{tabular}




\section{JURNAL INOVASI \\ FARIMASI INDONESIA}

(JAFI)

Walaupun hasil penelitian menunjukkan lebih banyak pasien yang mempunyai nilai kadar gula darah buruk (>126 mg/dl), namun terlihat terjadi penurunan jumlah pasien dengan kadar gula darah buruk di setiap pemeriksaan. Hasil ini menggambarkan dengan melakukan kontrol kadar gula darah puasa secara teratur dapat mengurangi jumlah pasien yang mempunyai nilai kadar gula darah buruk. Penelitian yang dilakukan Lafata et al., (2013) juga menyebutkan bahwa dengan melakukan kontrol kadar gula darah puasa secara teratur memiliki hubungan yang signifikan terhadap tingkat kadar gula darah pasien DM. Semakin rutin pasien melakukan kontrol kadar gula darah puasa dan sesuai jadwal maka nilai kadar gula darahnya akan semakin baik. Hal tersebut sesuai dengan penelitian yang dilakukan.

\section{HbA1C}

Hasil penelitian menunjukkan bahwa tidak ada pasien yang menunjukkan hasil kestabilan baik sebelum dan sesudah JKN. jumlah pasien yang melakukan pemeriksaan 56 pasien sebelum JKN dan 47 pasien sesudah JKN. Hal tersebut dikarenakan pasien tersebut tidak memenuhi persyaratan, dimana tidak ada pasien yang melakukan pemeriksaan rutin pada 3 bulan terakhir periode sebelum dan sesudah JKN.

Berdasarkan hal tersebut diharpakan bahwa pemeriksaan HbA1C dapat dilakukan secara rutin, karena pemeriksaan HbA1C merupakan parameter utama untuk pasien DM tipe II. Pemeriksaan dilakukan untuk melakukan terapi dan mengetahui keberhasilan terapi, sehingga hal tersebut mencegah dan menurunkan komplikasi pada pasien yang dapat meningkatkan kualitas hidup pasien.

\section{KESIMPULAN}

Penurunan biaya pengobatan sesudah pelaksanaan program JKN dikarenakan RS dapat menyesuaikan tarif Ina-CBGs yang sudah ditentukan oleh pemerintah yang ditunjukkan adanya perbedaan tarif rumah sakit dan tarif Ina-CBGs. Walaupun adanya pengaruh terhadap biaya dan profil pengobatan sesudah JKN, hal tersebut tetap dapat mempengaruhi clinical outcomes yang dapat dilihat dengan adanya penurunan jumlah pasien dengan kadar gula darah buruk di setiap pemeriksaan.

\section{DAFTAR PUSTAKA}

American Diabetes Association (ADA). 2014. Standar of Medical Care in Diabetes. Diabetes Care. Volume 37. Supplement 1.

Badan Penelitian Dan Pengembangan Kesehatan RI. 2013. Riset Kesehatan Dasar (Riskesdas) 2013: Jakarta.

Bintanah, S., Erma, H. 2012. Asupan Serat dengan Kadar Gula Darah, Kadar Kolesterol Total dan Status Gizi Pada Pasien Diabetes Melitus Tipe 2 Di Rumah Sakit Roemani Semarang. LPPM Unimus. Jurnal : 978.

Dirjen Bina Kefarmasian dan Alat Kesehatan. 2014. Keputusan Direktur Jenderal Bina Kefarmasian Dan Alat Kesehatan NOMOR HK.02.03/III/1346/2014 Tentang Pedoman Penerapan Formularium Nasional: Jakarta.

Indonesian Renal Registry. 2011. 4th Report Of Indonesian Renal Registry, IRR: 18-20.

Kemenkes RI. 2013. Riset Kesehatan Dasar Tahun 2013, Kementrian Kesehatan Republik Indonesia: Jakarta.

Kemenkes RI. 2013. Riskesdas Dalam Angka Provinsi Jawa Tengah 2013. Kementerian Kesehatan Republik Indonesia: Jakarta. 


\section{JURNAL INOVASI \\ FARMASI INDONESIA}

(JAFI)

Kemenkes RI. 2014. Buku Pegangan Sosialisasi Jaminan Kesehatan Nasional (JKN) Dalam Sistem Jaminan Sosial Nasional. Kementerian Kesehatan Republik Indonesia : Jakarta.

Kementerian Kesehatan Republik Indonesia. Situasi dan Analisis Diabetes. Pusat Info Data Dan Informasi Kementerian Kesehatan Republik Indonesia. Pusat Data Dan Informasi. Jakarta. 2014.

Lafata, J.E., Morris, H.L., Dobie, E., Heisler, M., Werner, R.M., Dumenci, L.. 2013. PatientReported Use Of Collaborative Goal Setting and Glycemic Control Among Patients With Diabetes. Patient Educ Couns [Internet]. Elsevier Ireland Ltd. 92(1): 94-9.

Meryta, A., Anggriani, Y., dan Kusumaeni, T. 2015. Pengaruh Penerapan Jaminan Kesehatan Nasional BPJS Terhadap Biaya Pengobatan, Clinical Outcomes, dan HRQoL Pasien Askes DM tipe II Rawat Jalan di RSUP Persahabatan. Tesis. Magister Ilmu Kefarmasian Universitas Pancasila Jakarta.

Padmawati. 2014. Hospital Administration Conference II. Tema: "Wajah Pelayanan Kesehatan Indonesia. Dalam CEA FKM UI. Jakarta. HIm: 15, 40, 435.

Pontoan, J., Anggriani, Y., dan Sabirin, B.P. 2015. Evaluasi Profil Pengobatan dan Biaya, Clinical Outcomes Sebelum dan Sesudah JKN Serta HRQoL Pada Pasien DM Tipe 2 Di RSUD Tarakan. Tesis. Magister Ilmu Kefarmasian Universitas Pancasila Jakarta.

Undang-undang Republik Indonesia. 2009. Tentang Rumah Sakit Nomor 44. Presiden Republik Indonesia.

Undang-undang Republik Indonesia. 2011. Tentang Badan Penyelenggaraan Jaminan Sosial Nomor 24. Presiden Republik Indonesia.

Undang-undang Republik Indonesia. 2014. Tentang Kesehatan Nomor 36. Presiden Republik Indonesia.

Widyastuti, R.. 2014. Korelasi Lama Menjalani Hemodialisis dengan Indeks Massa Tubuh Pasien Gagal Ginjal Kronik di RSUD Arifin Achamad provinsi Riau. Jurnal Gizi: 1(2). 